\title{
3D-Model of Personnel Innovative Competencies of Self-Developing, Self-Organizing Systems
}

\author{
Andrunik Andrey \\ Department of Management and Marketing, PNIPU, 614990, Perm, Russia \\ Email (corresponding author): andrunik72@mail.ru
}

\begin{abstract}
The personnel behavior modelling performs an objective function of strategic competent planning on key groups of innovative reserve of enterprise personnel. However, the analysis of a new paradigm «Management 2.0» permits to make the following conclusion - the question on the model development of innovative competencies, which are interconnected by coherent management system and able to propel HRM to a completely new level, remains open. Therefore, the main research objective of this work is to form an innovative competencies model focused on the realization of new management paradigm with dominating self-development and self-organization processes.
\end{abstract}

Keywords: Self-developing, Self-organizing systems (2S-systems), 2S-competencies, Competencies clusters, Innovative 3D-model of personnel behavior

\section{Introduction}

Important theoretical and methodological prerequisite for creation of technologies complex for enterprise innovative development management is realization of the requirement of process fundamental analysis with the use of scientific methods, one of which is modelling. At the same time the technification of HRM is not only considered as the main source of competitive advantages of the enterprise, but also as a basic condition for possibility of management transition to a new development stage. The survey «Talent Edge 2020: Blueprints for the new normal» conducted in 2010 by Deloitte company shows that highly skilled personnel is a focus of attention in a global and emerging markets for more than $41 \%$ of 330 interrogated senior managers of large HRM companies. $72 \%$ of respondents predict substantial and moderate personnel deficit in R\&D sphere in the nearest decade. R\&D-skills deficit especially dominates in those economy spheres, where innovative products creation is more critical for the economic growth and the innovations are the source of new jobs.

\section{Setting of research tasks}

The analysis of 25 moon shots (Hamel G., 2009), formulated by famous scientists and chiefs of large companies in the context of a new paradigm "Management 2.0", permits to make the following conclusion - the development question of new programs, models and innovative competencies, which are interconnected by coherent management system and able to propel HRM to a whole new level, remains open. Research of Russian and foreign consulting companies activity, which render service on personnel assessment to determine personnel correspondence to competencies strategic models, shows that peculiarities of diagnostic method use are not developed in modern sources. Therefore they cannot be used in practice. For this reason, the main research task of this work is formation of innovative competence model, oriented towards realization of new management paradigm with dominating processes of selfdevelopment and self-organization.

In economic literature, the development of business entity is mainly presented as the systems of corporate entrepreneurship with the main role of administrative core (holder, board of management, top management). An employee is not considered as active subject of labor activity, but as personnel, human resource or capital. Therefore during the development of innovative personnel competencies model of self-developing and self-organizing systems 
(2S-competencies) it is necessary to take into account not only competencies of professional, personal and qualifying nature, but also behavioral competencies (Andrunik A.P., 2012). It implies that for a comprehensive assessment of 2Scompetencies it is necessary not to summarize the results of their achievements, but to reveal the dependences between competencies and between their elements. Only in this case it is possible to assess objectively the results of labor behavioral and personnel activity and to make a right conclusion about correspondence of employee to his position and about capacity (or incapacity) to self-development. The behavior diagnosis of $2 \mathrm{~S}$-system personnel must be realized in 3 basic directions: professional, personal and behavioral. For this reason, it makes sense to build three-dimensional model of personnel behavior on enterprise, when forming the model of $2 \mathrm{~S}$-competencies diagnosis and development. $3 \mathrm{D}$ modelling is a process of three-dimensional model creation of an object, elaboration of its visual volume image, which reflects peculiarities and links significant for a solvable problem. There are several types of 3D-design in theory and methodology of three-dimensional graphics. In this work, an object-oriented type was used. This type of visual reproduction gives the objects that consist of related sets of shaping lines, segments, links and volumes. 3D-model of personnel behavior in 2S-system is represented in (Fig.1)

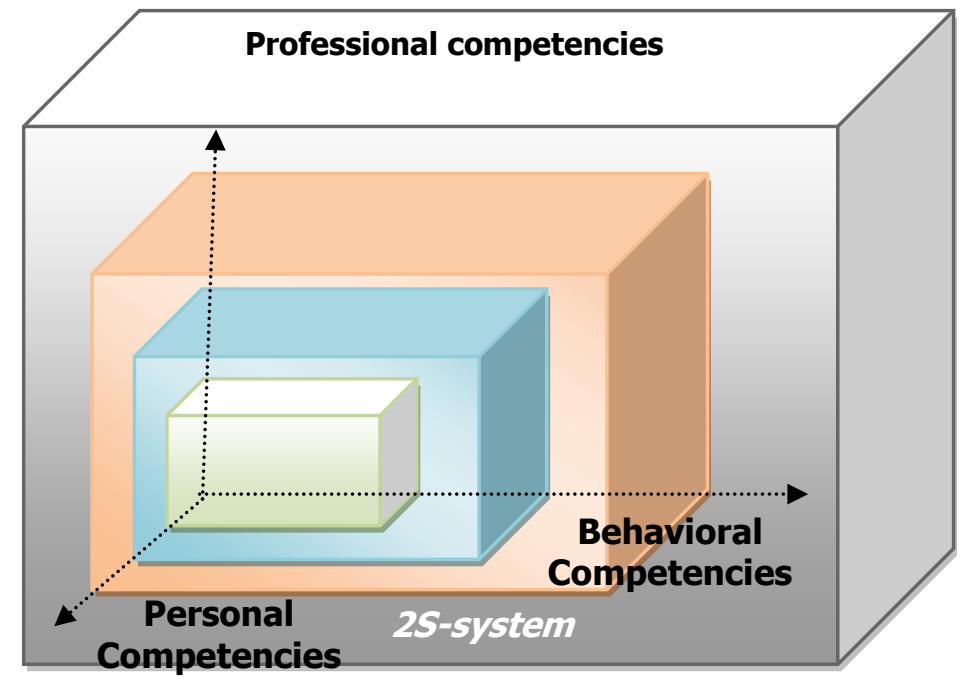

Figure 1: 3D-model of personnel behavior in 2S-system

The model represents 3 dimensions of personnel behavior in 2S-system, which are actualized in specific activity. Each dimension depending on maturity (immaturity) determines a formedness level of personnel specific $2 \mathrm{~S}$-competencies. It implies that in the matter of professional behavior it makes sense to examine behavior stability level of personnel. It seems that basic $2 \mathrm{~S}$-competencies model must include list of main $2 \mathrm{~S}$-system elements with competencies clusters predetermined to actual activity sphere and with behavior indicators corresponding to clusters (tab. 1). If the competencies have stable state, there is an opportunity of situation predictability: when a specialist has in store a sufficient number of competencies, a situation of possible grouping of competencies and consequences of such grouping appears. Competencies and behavioral indicators of matrix are revealed on basis of interview with leading company experts and are correlated with competencies lists, dictionaries and clusters used in practice of Russian companies, European institutes and research centers for management problematic of personnel innovative competencies. 
Table 1: 2-S competencies matrix

\begin{tabular}{|c|c|c|c|}
\hline Non & Competence cluster & \multicolumn{2}{|r|}{ Competencies } \\
\hline \multirow[t]{3}{*}{1} & \multirow{3}{*}{$\begin{array}{l}\text { UNITY OF GOALS AND INTERESTS OF } \\
\text { INDIVIDUALS, GROUPS, COMPANIES } \\
\text { The characteristic reflects how personnel goals coincide } \\
\text { with subdivisions and company goals, how employee } \\
\text { behavior vector coincides with necessary line of enterprise } \\
\text { development. }\end{array}$} & 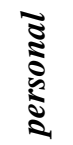 & $\begin{array}{c}\text { Capacity to accept corporate goals and } \\
\text { values }\end{array}$ \\
\hline & & $\widetilde{\Xi}$ & Capacity to determine priorities \\
\hline & & $\stackrel{P}{2}$ & Capacity to solve problems \\
\hline \multirow[t]{3}{*}{2} & \multirow{3}{*}{$\begin{array}{l}\text { TAKING RESPONSIBILITY, SELF-CONTROL } \\
\text { The characteristic shows employee readiness to take the } \\
\text { responsibility for initiatives realization, to control } \\
\text { independently movement toward a desired result }\end{array}$} & \multirow{2}{*}{ 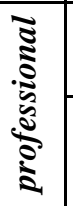 } & $\begin{array}{l}\text { Capacity to make daily decisions and to } \\
\text { ensure their realization }\end{array}$ \\
\hline & & & $\begin{array}{l}\text { Capacity to execute self-control of } \\
\text { performed work quality }\end{array}$ \\
\hline & & 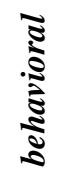 & $\begin{array}{l}\text { Capacity to be responsible for results of } \\
\text { professional and administrative activity }\end{array}$ \\
\hline \multirow{5}{*}{3} & \multirow{5}{*}{$\begin{array}{l}\text { MULTILEVEL LEADERSHIP, TEAM WORK, } \\
\text { SYNERGETICS, ENGAGEMENT } \\
\text { (MECHANICAL) } \\
\text { Behavioral models and precedents that contribute for } \\
\text { teamwork, adherence, engagement, synergies of individual } \\
\text { exertions, build personal and team success in a company. }\end{array}$} & \multirow{3}{*}{ ฐँ } & Emotional stability \\
\hline & & & Stress resistance \\
\hline & & & $\begin{array}{l}\text { Capacity to be fair and honest toward } \\
\text { others }\end{array}$ \\
\hline & & \multirow{2}{*}{ 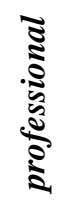 } & Capacity to build relations within group \\
\hline & & & Crew member \\
\hline \multirow{4}{*}{4} & \multirow{3}{*}{$\begin{array}{c}\text { INSIDE LONG-RANGE MOTIVATION AND ITS } \\
\text { TENSION (MOVER) }\end{array}$} & \multirow{3}{*}{$\bar{\Xi}$} & Foresight \\
\hline & & & Capacity to determine strategic aims \\
\hline & & & $\begin{array}{l}\text { Employee orientation at the market and } \\
\text { consumption }\end{array}$ \\
\hline & $\begin{array}{l}\text { People demonstrate adherence to company values and } \\
\text { interests, they are initiative and involved in change processes, } \\
\text { they support new ideas, attack creatively regular and new } \\
\text { problems, solidarity and team work are key characteristics of } \\
\text { colleagues. }\end{array}$ & 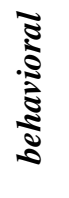 & $\begin{array}{l}\text { Strength of motivation and its } \\
\text { orientation (behavior vector) }\end{array}$ \\
\hline \multirow{3}{*}{5} & \multirow{3}{*}{$\begin{array}{l}\text { DECENTRALIZATION AND INTRAPRENEUSHIP } \\
\text { Formal rules and protocols, which contribute for initiative } \\
\text { display, permit to make and to realize administrative and } \\
\text { technologic decisions independently. }\end{array}$} & \multirow{3}{*}{ 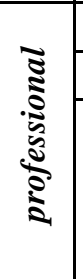 } & Communicative skills \\
\hline & & & Capacity to affect and influence \\
\hline & & & Entrepreneurial skills \\
\hline \multirow[t]{2}{*}{6} & \multirow[t]{2}{*}{$\begin{array}{l}\text { SELF-EDUCATION, KNOWLEDGE } \\
\text { ACCUMULATION AND EXCHANGE }\end{array}$} & \multirow{2}{*}{ 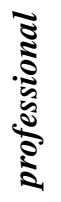 } & Capacity to work with information \\
\hline & & & Cognitive capability \\
\hline
\end{tabular}




\begin{tabular}{|c|c|c|c|}
\hline & $\begin{array}{l}\text { Employees are able to find independently all necessary } \\
\text { information. The best experience is quickly distributed } \\
\text { among subdivisions. Existent databases of a company allow } \\
\text { finding necessary information. Colleagues are ready to share } \\
\text { experience with each other. }\end{array}$ & & $\begin{array}{l}\text { Self-education and self-development } \\
\text { culture }\end{array}$ \\
\hline \multirow[t]{3}{*}{7} & \multirow{3}{*}{$\begin{array}{l}\text { DISPLAY OF INITIATIVE AND ACHIEVEMENT OF } \\
\text { MAXIMUM RESULT } \\
\text { Employees display their initiative in getting of new } \\
\text { knowledge, in its appliance, in realization of advanced } \\
\text { initiatives. Employees' work is aimed to the achievement of } \\
\text { the maximum result. }\end{array}$} & $\begin{array}{l}\widetilde{\Xi} \\
\vdots \\
\vdots \\
\vdots \\
\vdots \\
\vdots\end{array}$ & $\begin{array}{c}\text { Capacity to organize colleagues for task } \\
\text { solution }\end{array}$ \\
\hline & & \multirow{2}{*}{$\frac{\sqrt[3]{2}}{\mathfrak{5}}$} & $\begin{array}{l}\text { Capacity to contribute for individual } \\
\text { goal setting }\end{array}$ \\
\hline & & & Capacity to inspire for idea development \\
\hline
\end{tabular}

Appliance of this 2S-competencies model permits to determine quickly and impartial the level of specialists readiness for task performance on professional intention in $2 \mathrm{~S}$-systems, to compare the results, generated in diagnosis of personnel development level in different periods of time, to estimate efficiency of people management in $2 \mathrm{~S}$-systems and to determine directions of senior officers activity for drawing up programs of personal growth of personnel professional development.

\section{Determination of $2 \mathrm{~S}$-competencies development level}

Personnel studies of several large companies in Perm krai permitted to give a general psychological and pedagogical characteristic to each of revealed types. Low level of $2 S$-competencies (situational behavior) is marked by the poor development of 3 types of competencies (pic.2 - fig.1). A situational behavior is regarded as a type of behavior, characterized by "pressure" (according to R.A. Pavligina) of situations that actualize corresponding employee needs, which it is possible to hope for or it should be beware of.

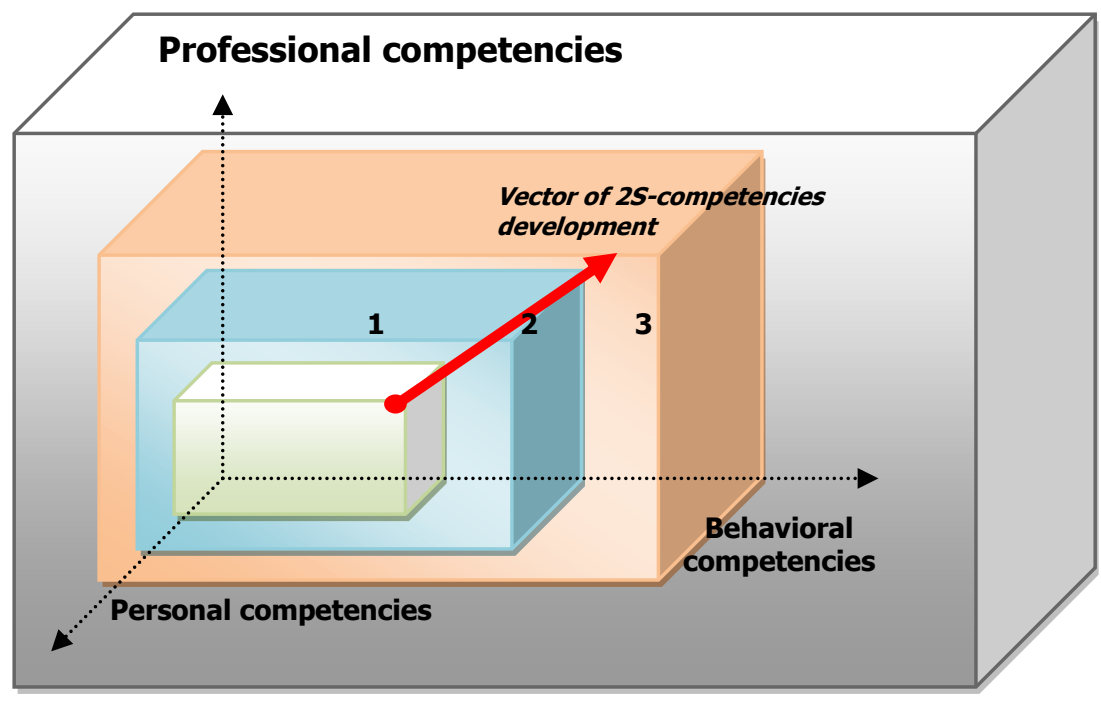

Figure 2: Vector of 2S-competencies development

Such behavior type is due to an unestablished value system and to unstable behavioral stereotype. According to special research personnel with a situational behavior is characterized by an unstable motivational sphere and, as consequence, by excessive influence-ability. Response to requests from outside is selective and egoistic; susceptibility to administrative influence is contradictive. Such employees can be characterized by the lack of aspiration for selfdevelopment, improvement and hardening of their place in collectivity. Socially important goals are absent, needs are unessential, primitive and mostly financial, motives are not marked by a well-defined desire to work in the collective and in a company in general. Behavior vector coincides with the necessary direction of enterprise development, but only in part of corporate goals acceptance. At the same time personnel with a situational behavior is able to control 
emotions well and to satisfy objectives regardless of emotional state. In work situations such employees keep an open mind to colleagues, they do what they recognize important, but have a high level of anxiety. Employees with situational behavior understand directions of medium term development and can prioritize works, portioning out resources and working time. Capacity to estimate options of problem decisions is underdeveloped. Such people usually follow the predetermined decisions making procedures, but only within a framework of their own professional adequacy, which is also underdeveloped. Taking adequately the situation of communication, personnel with this type of behavior understand the reasons of difficulties appearing, keep in touch with people during communication, abstracting away from their personal opinions and thoughts. Readiness for taking responsibility for initiatives realization, for independent control of movement toward necessary result is weak. Personnel of this behavioral type can schedule activity in a company and analyze possible risks. The state of physical health is satisfying, but the psychological state is marked by deliberation, inactivity, impatience, emotional intension and underdevelopment of volitional powers. Success lifts spirits and small troubles can provoke an affect in the form of anger, aggression and rudeness.

Mean level of 2S-competencies development (stereotyped behavior) is represented by figure 2 (pic.2).

Stereotyped behavior is characterized by a set of certain standardized collective rules, experience, which help personnel to orientate in life, to follow corporate values and to direct the vector of personnel behavior (according to R. A. Pavligina). The results of conducted research show that employees with this type of behavior make decisions with an account of company interests. Behavioral models and precedents that contribute for teamwork, adherence, engagement, synergies of individual exertions, are promoted. At the talks, such employees pursue win-win results, preserving work effectiveness with an increase of uncertainty level. The anxiety level is mean or related to low. This personnel speaks simply and without negotiants about their intentions, ideas and feelings, choose the most effective means to organize colleagues for task execution, avoid a negative influence of their activity on others. They make decisions in an emergency well timed and are able to forecast consequences of these decisions, determining necessary resources for problem solving. Personnel with stereotyped behavior usually demonstrate adherence to company values and interests. They are initiative and engaged in change processes employees, who support new ideas and perform creatively new tasks. Solidarity and teamwork are key characteristics of work in a company. Such employees express their view logically, using facts as arguments, but not emotions. Their work is aimed at maximum result achievement. At this time, they can determine well-timed and independently correct criterions of success and of activity valuation. Personnel with this behavior type are able to find all necessary information all by themselves. They display their initiative in getting of new knowledge, in its appliance, in realization of advanced initiatives. Employees' work is aimed to choose the most effective means to organize colleagues for task execution. Such personnel actively perceive and think over ideas, advanced by colleagues, developing new methods and practice of ideas realization.

\section{High level of 2S-competencies development (stable behavior) is represented by figure 3 (pic.2).}

Stable behavior is characterized by a balance between constancy of main personal principles (goals, dominant motives, ways of behavior) and changeability of personality (dynamics of motives, the appearance of new behavior ways, search for new work methods, the performance of new reaction forms on situations). A behavioral stability is manifested through dominants of activity, self-knowledge, self-regulation, dynamic development, and adaptation in a company and, as a consequence, an efficient functioning. Personnel with stable behavior empower, match the level of personal tension with psycho and organism resources, and minimize a detrimental effect of a subjective constituent of this tension. Such employees have the capacity to resist things that curtail behavior freedom, freedom of decision choice and of mode of life in general. The most important constituent of this resistance is the self-sufficiency of personality, understood as one-wayness of employee behavioral activity and company behavior vector. The results of conducted research show that goals of such personnel coincide with subdivision and company goals. At the same time, employees are ready to sacrifice personal interests for collective ones. They adequately take different company changes, understand their significance and do not feel internal discomfort. Employees with a stable behavior measure a weight of their activity through consequences of its performance or underperformance. They are ready to take responsibility for initiatives realization, to control independently the movement toward necessary result and to make tough sells, if it is required. These personnel approach responsibly to task performing, sustain and elevate professional and personal image. In relations with colleagues they follow behavioral models and precedents that contribute for teamwork, adherence, engagement, synergies of individual exertions, consider different cultural styles of team understanding the value of team activity. They have low anxiety level, are able to see long-range goals and re-evaluate adopted experience in the context of getting new information and changing conditions. Personnel can not only determine development directions in the sphere of company strategic activity, but also participate in formulation of long-term 
goals. They display initiative as a readiness to work more, faster and out of bounds of instructions, they are unclosed and ready to share the experience with each other, demonstrating a need for a new knowledge. They are able to find resources for maintaining of self-education on all levels of organizations, ensure inspiration of colleagues for education by activity procedures and processes; they understand that self-development contributes for general company development. At the same time, this personnel can collate self-education goals with methods of information acquiring. They display innovation and a creative approach in a professional activity, actively perceive and think over ideas, advanced by colleagues and take part in idea production events. Capacity for self-direction, mediation of behavior is considered as the most important criterion of individual development.

As discussed, the function of each level consists in influence on each other. Changes on the high-level cause changes on lower ones, but changes on low levels need not to cause changes on higher levels. Analysis of investigation results allows exposing of strong regular and content-related bonds: based on situational behavior the persistent stereotypes form, which in turn develop into dominants of personnel self-development and into a robust behavioral response.

This means that basing on regularity of employee development; it is possible to talk about stages of employee creative development, i.e. to consider him as self-developing system. In this case, it is necessary to take into account such essential characteristic of development as procedurality. It should be emphasized that identifying the level of competence linked with self-development, it needs to use directions due to suprasituational activity of subjects participating in process of competencies formation. At that it is necessary to ensure conditions for self-development of professional, personal and behavioral competencies.

\section{Conclusion}

Thus, in forming of integral model of $2 \mathrm{~S}$-competencies diagnostics it makes sense to work out a phased plan of development of each specialist, a development dynamics and to determine competencies that need to be improved in future. For this, it is necessary to describe diagnostic "line-example" (pic.5 - vector of $2 \mathrm{~S}$-competencies development) that will comport with principles of $2 \mathrm{~S}$-systems building. $2 \mathrm{~S}$-systems make possible to determine stability (instability) of specific behavioral characteristics, possibility to predict personnel behavior in specific (regular/stressful) situations, to form an image of professional behavior and to forecast possible subjective development in a specific profession.

\section{References}

- Andrunik A.P. Inovatsionnye tekhnologii upravleniya personalom [Innovative technologies of HRM. Part 2.] 2009. 278p. (rus);

- Andrunik A.P., Molodchik A.V. Metodologiya upravleniya personalom v samoorganizuyushchikhsya, samorazvivayushchikhsya innovatsionnykh organizatsiyakh [Methodology of HRM in self-organizing, selfdeveloping innovative companies]. Vestnik universiteta (Gosudarstvennyy universitet upravleniya) [Newsletter of University (State University of Management). Moscow. UM]. 2012. №1. (rus);

- Annual Results 2010, AstraZeneka, 2010 // http: // www.astrazenecaannualreports.com/AZ_AR_100311_single.pdf;

- Hemel G. Management 2.0: the new version for a new century. Harvard Business Review (HBR), October 2009 ; 